\title{
Panorama da Evasão no Curso de Sistemas de Informação da Universidade Federal de Uberlândia: Um Estudo Preliminar
}

\author{
Ieza L. Damasceno ${ }^{1}$, Murillo G. Carneiro ${ }^{1}$ \\ ${ }^{1}$ Faculdade de Computação - Universidade Federal de Uberlândia (UFU) \\ Uberlândia, MG, Brasil \\ ieza.lopes.7@gmail.com, mgcarneiro@ufu.br
}

\begin{abstract}
This paper presents an ongoing methodology to create and analyze the dropout panorama of the students in the undergraduate course of Information Systems at Universidade Federal de Uberlândia from data provided by the academic control system of the university. The methodology comprises the data organization, the calculation of dropout rates and the analysis of the panorama obtained in terms of distinct factors. The results show a panorama with high dropout rates besides a preliminar discussion about some possible related factors. Forthcoming investigations aim to analyze and compare other two undergraduate courses of the university which are also related to the computer science area but have distinct characteristics.
\end{abstract}

Resumo. Este artigo apresenta uma metodologia em desenvolvimento para estabelecer e analisar o panorama da evasão de discentes em cursos de computação da Universidade Federal de Uberlândia. Especificamente, o estudo é conduzido a partir de dados do curso noturno de Bacharelado em Sistemas de Informação (campus Santa Mônica), os quais são providos pelo sistema de controle acadêmico da universidade. A metodologia compreende a organização dos dados, o cálculo de medidas de evasão e a análise do panorama obtido a partir de diferentes fatores relacionados ao curso (periodo, perfil do aluno, etc.). Os resultados mostram um panorama com percentuais de evasão elevados além de apresentar uma análise preliminar sobre alguns fatores que podem estar relacionados. As investigações subsequentes pretendem analisar e comparar outros dois cursos de computação da universidade com características distintas.

\section{Introdução}

A evasão é um problema de proporções cada vez maiores para instituições de ensino superior públicas e privadas, pois causa perdas econômicas, sociais e acadêmicas [Silva Filho et al. 2007]. Em poucas palavras, o termo evasão se refere ao abandono do curso pelo discente sem a devida conclusão do mesmo [Bardagi and Hutz 2005]. Apesar de receber atenção crescente por parte dos educadores e pesquisadores, ainda são poucos os trabalhos que abordam a evasão de maneira quantitativa. Na maioria dos casos, os trabalhos contemplam revisões e análises da teoria por trás do assunto, como por exemplo, as principais causas e agentes envolvidos [Comissão Especial de Estudo de Evasão 1996, Morosini et al. 2011].

Além das instituições de ensino superior, a evasão também afeta outros setores ligados ao âmbito acadêmico, em especial o mercado de trabalho. Com enfoque no mercado de TI, um estudo realizado pela empresa CISCO em 2016 analisou a demanda em 
VII Congresso Brasileiro de Informática na Educação (CBIE 2018)

Anais do XXIX Simpósio Brasileiro de Informática na Educação (SBIE 2018)

habilidades voltadas para a área de redes de computadores em 10 países da america latina, e constatou na análise regional que o Brasil em 2015 apresentou uma lacuna de 195.365 prossionais naquela área [Pineda and Gonzalez 2016].

Dada a relevância do assunto, este artigo tem como objetivo principal estabelecer um panorama quantitativo da evasão de discentes no curso noturno de Bacharelado em Sistemas de Informação (campus Santa Mônica), na Universidade Federal de Uberlândia (UFU) tomando em consideração dados providos pelo sistema de controle acadêmico da universidade. A partir de uma metodologia em desenvolvimento, a qual compreende a organização dos dados, o cálculo de medidas de evasão e a análise do panorama obtido sob diferentes fatores, almeja-se fornecer estimativas concretas para auxiliar a direção da unidade a mensurar o índice de desistência dos discentes em relação ao referido curso superior, bem como na elaboração de medidas de combate ao problema.

\section{Metodologia}

A metodologia utilizada na análise de dados compreende três fases: a organização dos dados dos discentes (ingressos, diplomações e desligamentos), aplicação de métricas relacionadas à evasão e a análise de resultados.

1. Organização dos dados: os dados foram obtidos através do sistema de controle acadêmico da universidade e registram informação dos alunos no período de 2009 a 2017 em relação às seguintes situações: ingresso, evasão, trancamento e diplomação. Eles foram organizados pelo período de ingresso das turmas.

2. Métrica de evasão: o cálculo da taxa de evasão é dado pela fórmula

$$
E(n)=\frac{D(n) \cdot 100}{I(n)}
$$

onde n denota uma turma de ingressantes em um dado período, $\mathrm{I}(\mathrm{n})$ a quantidade de alunos ingressantes em $\mathrm{n}, \mathrm{D}(\mathrm{n})$ o número de desligamentos sem diplomação em n, e E(n) a taxa de evasão de $n$.

3. Análise de resultados: analisar e interpretar os resultados obtidos em função das particularidades do curso e de seus alunos bem como propor ações para diminuir os índices de evasão. Esta etapa ainda não está concluída devido à extensa lista de fatores existentes para avaliação.

\section{Resultados Preliminares}

\subsection{Organização dos dados}

A Tabela 1 apresenta a organização dos dados de alunos evadidos considerando individualmente as turmas de ingressantes de 2009/1 à 2013/2 durante o período de 2009/1 até 2017/2. Por exemplo, a tabela mostra que 9 alunos da turma de 2009/2 deixaram o curso em 2013/1. Em suma, as informações contidas nessa tabela são relevantes tanto para estabelecer um panorama relacionado à evasão de cada turma quanto para análises específicas relacionadas a turmas de ingresso em diferentes períodos. 
VII Congresso Brasileiro de Informática na Educação (CBIE 2018)

Anais do XXIX Simpósio Brasileiro de Informática na Educação (SBIE 2018)

Tabela 1. Número de alunos evadidos nas turmas de ingressantes do curso noturno de Sistemas de Informação da UFU entre o período de 2009/1 e 2017/2.

\begin{tabular}{|c|c|c|c|c|c|c|c|c|c|c|c|c|c|c|c|c|c|c|c|}
\hline & 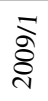 & 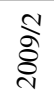 & $\begin{array}{l}\bar{\Xi} \\
\stackrel{i}{a}\end{array}$ & 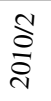 & $\underset{\Xi}{\bar{\Xi}}$ & 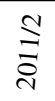 & 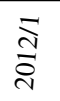 & $\frac{\stackrel{N}{d}}{\stackrel{i}{a}}$ & $\frac{\bar{m}}{\stackrel{i}{\sim}}$ & $\frac{\stackrel{N}{2}}{\stackrel{d}{d}}$ & $\frac{\bar{f}}{\vec{d}}$ & $\frac{\mathfrak{d}}{\stackrel{d}{d}}$ & $\frac{\sqrt{n}}{\bar{i}}$ & $\frac{\sqrt{n}}{\frac{i}{\pi}}$ & $\frac{\bar{\delta}}{\stackrel{i}{\pi}}$ & $\frac{\mathfrak{d}}{\stackrel{d}{a}}$ & $\frac{\sqrt{5}}{\stackrel{i}{a}}$ & $\frac{\mathbb{N}}{\frac{i}{d}}$ & $\stackrel{\widetilde{\Xi}}{\bullet}$ \\
\hline $2009 / 1$ & 2 & & & 3 & & 4 & 13 & 1 & 6 & 2 & 2 & & 2 & & 2 & & & & 37 \\
\hline $2009 / 2$ & & 2 & & 1 & 3 & 3 & 14 & 2 & 9 & 3 & 3 & 1 & 1 & & 2 & & & 2 & 46 \\
\hline 2010/1 & & & 1 & 1 & 1 & 2 & 8 & & 9 & 4 & 1 & 2 & & 1 & 3 & & & 3 & 36 \\
\hline $2010 / 2$ & & & & 1 & 3 & 1 & 7 & 4 & 8 & 7 & 5 & 4 & & & 2 & 2 & & 4 & 48 \\
\hline 2011/1 & & & & & 1 & 1 & 3 & 2 & 10 & 5 & 8 & 5 & 1 & 1 & 6 & & & 1 & 44 \\
\hline $2011 / 2$ & & & & & & & 1 & 1 & 2 & 6 & 5 & 4 & 1 & & 7 & & & 5 & 32 \\
\hline $2012 / 1$ & & & & & & & 5 & & 4 & 9 & 7 & 6 & 3 & & 8 & & & 3 & 45 \\
\hline $2012 / 2$ & & & & & & & & 1 & 1 & 2 & 5 & 4 & 4 & & 19 & & & 7 & 43 \\
\hline 2013/1 & & & & & & & & & 10 & 2 & 2 & 1 & 3 & 2 & 29 & & 1 & 3 & 53 \\
\hline $2013 / 2$ & & & & & & & & & & 2 & 3 & 1 & 1 & 2 & 19 & & 4 & 8 & 40 \\
\hline Total & 2 & 2 & 1 & 6 & 8 & 11 & 51 & 11 & 59 & 42 & 41 & 28 & 16 & 6 & 97 & 2 & 5 & 36 & 424 \\
\hline
\end{tabular}

\subsection{Taxa de evasão e análise dos resultados}

A Tabela 2 apresenta o cálculo da taxa de evasão de cada turma considerada no estudo. Os resultados mostram que os índices de evasão são elevados, chegando a até $72 \%$ na turma 2010/2. Entre as prováveis razões para explicar esses índices de abandono estão relacionadas às próprias características do curso, que por ser noturno é majoritariamente composto por discentes que trabalham em período diurno e possuem menor tempo disponível para o estudo extra-classe.

Tabela 2. Taxa de evasão das turmas de 2009/1 à 2013/2 do curso noturno de Sistemas de Informação da UFU.

\begin{tabular}{cccc}
\hline Turma & \#Ingressantes & \#Evadidos & $E(n)(\%$ Evasão) \\
\hline $2009 / 1$ & 60 & 37 & 61.67 \\
$2009 / 2$ & 63 & 44 & 69.84 \\
$2010 / 1$ & 63 & 33 & 52.38 \\
$2010 / 2$ & 61 & 44 & 72.13 \\
$2011 / 1$ & 65 & 43 & 66.15 \\
$2011 / 2$ & 60 & 27 & 45.00 \\
$2012 / 1$ & 68 & 42 & 61.76 \\
$2012 / 2$ & 68 & 36 & 52.94 \\
$2013 / 1$ & 91 & 49 & 53.85 \\
$2013 / 2$ & 65 & 28 & 43.07 \\
\hline
\end{tabular}

Outra análise interessante é apresentada pela Fig. 1, a qual apresenta um comparativo entre alunos ingressantes, retidos, evadidos e diplomados nas turmas de 2009/1 à 2013/2. Percebe-se que a quantidade de alunos evadidos nas turmas analisadas quase sempre supera $50 \%$ do número de alunos ingressantes, significando que uma parte considerável dos alunos abandonam o curso. Outro problema evidenciado por essa comparação é a quantidade de alunos retidos, isto é, que não concluíram o curso dentro do prazo regular definido pelo Projeto Pedagógico de Curso (4 anos). 
VII Congresso Brasileiro de Informática na Educação (CBIE 2018)

Anais do XXIX Simpósio Brasileiro de Informática na Educação (SBIE 2018)

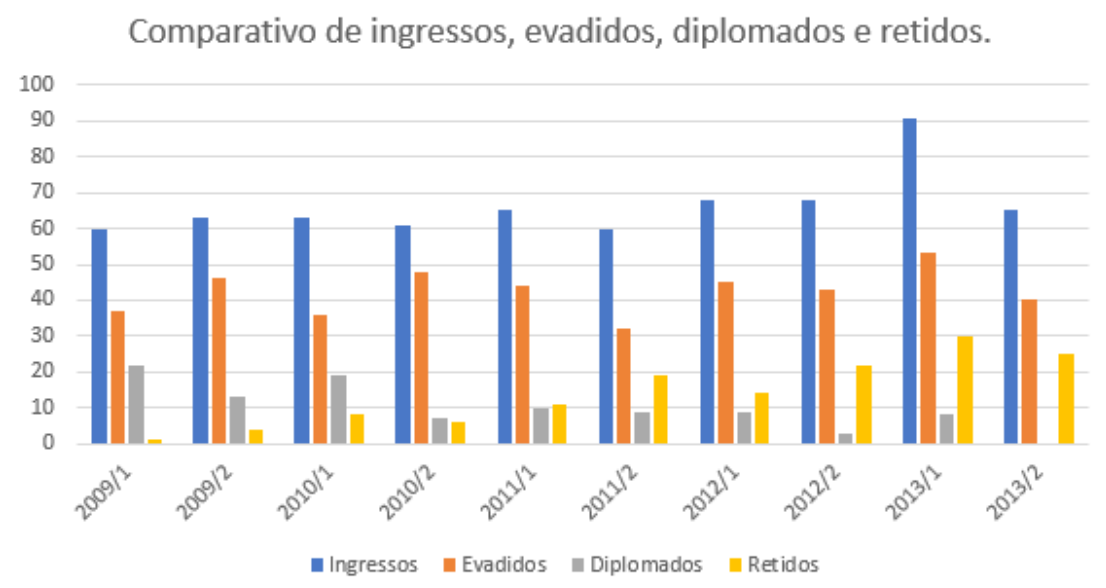

Figura 1. Comparativo entre alunos ingressantes, evadidos, retidos e diplomados do curso noturno de Sistemas de Informação da UFU nas turmas de 2009/1 à 2013/2.

Vale acrescentar que os dados sofreram alguma variação (ruído) devido a maneira que foram inseridos no sistema de controle acadêmico. Por exemplo, os dados de concluintes foram armazenados anualmente, enquanto os evadidos e retidos são semestrais. A interferência desse tipo de variação foi notada em algumas análises adicionais realizadas, nas quais as métricas aplicadas dependiam da quantidade de concluintes por semestre.

\section{Trabalhos Relacionados}

Em relação à análise de dados de evasão em cursos de computação, o trabalho apresentado em [Rodrigues et al. 2015] estudou o panorama da evasão da UFGRS, demonstrando a ocorrência da evasão no contexto histórico do curso de ciência da computação (apresentando dados de egressos nos anos de 1975 a 1979) e no aspecto mais atual (2000 a 2013), abordando de forma crítica a desistência de discentes por período. O estudo realizado pela comissão especial ANDIFES/MEC [Comissão Especial de Estudo de Evasão 1996] também lida com a evasão de maneira quantitativa para estimar a taxa de desistência nas universidades e instituições privadas com ênfase na definição de conceitos ambíguos, causas e prejuízos relacionados ao tema.

Outros trabalhos como [Palmeira and Santos 2015] levam em conta além dos fatores internos aos alunos (situação familiar, condição financeira e nível de escolaridade anterior) e fatores externos (infraestrutura do curso, apoio financeiro, metodologias acadêmicas), os atributos de interesse relacionados ao perfil dos discentes que evadem. Aliás, a modelagem de atributos para propor métodos de combate à evasão baseados em mineração de dados e aprendizado de máquina têm sido uma abordagem promissora na literatura [Martins et al. 2012, de Brito et al. 2014].

\section{Considerações Finais}

Este artigo apresenta os resultados preliminares de um estudo cujo objetivo é estabelecer o panorama da evasão nos três cursos de computação da Universidade Federal de Uberlândia. Especificamente, este estudo realizou a análise dos dados do curso noturno de Sistemas de Informação. Os resultados mostram um panorama com percentuais de evasão 
VII Congresso Brasileiro de Informática na Educação (CBIE 2018)

Anais do XXIX Simpósio Brasileiro de Informática na Educação (SBIE 2018)

elevados associado, provavelmente, a fatores relacionados às características próprias do curso e ao perfil dos alunos. Também merece destaque a evasão em massa de estudantes em determinados períodos (e.g., 97 discentes em 2016/1), cujas causas específicas serão investigadas em trabalhos futuros.

Por fim, o estudo abre espaço para os estudos subsequentes, onde os dados de outros dois cursos de programação da UFU serão analisados. Nesse sentido, vale ressaltar que a análise dos três cursos com características próprias e perfis de alunos diferentes pode prover um conjunto de fatores interessantes para caracterizar a evasão em cada um deles, bem como permitir o estudo e análise de diversas medidas de combate à evasão em diferentes contextos. Ao término de toda investigação, espera-se encontrar ou propor medidas e ações que diminuam efetivamente as taxas de evasão dos cursos considerados.

\section{Referências}

Bardagi, M. and Hutz, C. S. (2005). Evasão universitária e serviços de apoio ao estudante: uma breve revisão da literatura brasileira. Psicologia Revista, 14(2):279-301.

Comissão Especial de Estudo de Evasão (1996). Diplomação, retenção e evasão nos cursos de graduação em instituições de ensino superior públicas. Avaliação, 1(2):5565 .

de Brito, D. M., de Almeida Júnior, I. A., Queiroga, E. V., and do Rêgo, T. G. (2014). Predição de desempenho de alunos do primeiro período baseado nas notas de ingresso utilizando métodos de aprendizagem de máquina. In Brazilian Symposium on Computers in Education (Simpósio Brasileiro de Informática na Educação-SBIE), volume 25, page 882 .

Martins, L. C., Lopes, D. A., and Raabe, A. (2012). Um assistente de predição de evasão aplicado a uma disciplina introdutória do curso de ciência da computação. In Brazilian Symposium on Computers in Education (Simpósio Brasileiro de Informática na Educação-SBIE), volume 23.

Morosini, M. C., de Oliveira Casartelli, A., da Silva, A. C. B., dos Santos, B. S., Schmitt, R. E., and Gessinger, R. M. (2011). A evasão na educação superior no brasil: uma análise da produção de conhecimento nos periódicos qualis entre 2000-2011. In Conferencia Latinoamericana sobre el Abandono de la Educación Superior (CLABES), pages $1-10$.

Palmeira, L. B. and Santos, M. P. (2015). Evasão no bacharelado em ciência da computação da universidade de brasília: análise e mineração de dados. Monografia (graduação), Universidade de Brasília (UnB).

Pineda, E. and Gonzalez, C. (2016). Networking skills in latin america. Technical report, IDC.

Rodrigues, F., Brackmann, C. P., and Barone, D. A. C. (2015). Estudo da evasão no curso de ciência da computação da UFRGS. Brazilian Journal of Computers in Education, 23(01):97.

Silva Filho, R. L. L., Motejunas, P. R., Hipólito, O., and Lobo, M. B. C. M. (2007). A evasão no ensino superior brasileiro. Cadernos de pesquisa, 37(132):641-659. 